\title{
A case series of legionella pneumonia in the niagara region, canada
}

\author{
SM Cargnelli ${ }^{1}$, J Powis ${ }^{2,3,4}$, JLY Tsang ${ }^{1,5,6^{*}}$ \\ From ESICM LIVES 2015 \\ Berlin, Germany. 3-7 October 2015
}

\begin{abstract}
Introduction
Legionella pneumonia (LP), caused by Legionella pneumophila, was first recognized in 1976. Symptoms of LP include fatigue, myalgia, fever, headache, confusion, diarrhea, nausea, cough, hyponatremia and hypophosphatemia. LP accounts for $2-15 \%$ of all hospitalized communityacquired pneumonia (CAP) and carries a mortality rate of $15-25 \%$
\end{abstract}

\section{Objectives}

The objectives of this study are to

1) describe hospitalized LP cases in the Niagara Region, Ontario, Canada in 2013, and

2) to validate the Winthrop University Hospital (WUH) point score on our patient cohort.

\section{Methods}

We conducted a retrospective cohort study on all hospitalized LP cases in the Niagara Region, Ontario, Canada in 2013. Local research ethics approval was obtained. Patient data was extracted from electronic and paper medical records.

\section{Results}

Public Health Ontario has confirmed 17 cases of Legionellosis from June to December of 2013. 14 cases were hospitalized with LP. 13 cases of LP were confirmed with urinary antigen test. 1 case was confirmed by polymerase chain reaction of bronchial washing. The median age was 57 years, 8 patients (57\%) were men; $3(21 \%)$ had a history of ischemic heart disease, 9 (64\%) had hypertension, 5 (36\%) had diabetes, 2 (14\%) had chronic obstructive pulmonary disease, 4 (29\%) had chronic renal insuffi- ciency, 1 (7\%) had malignancy and $3(21 \%)$ were immunocompromised. $10(71 \%)$ were cigarette smoker and 3 (21\%) were cannabis users. The most common symptoms were fever $\left(71 \%\right.$; mean temperature, $\left.38.6^{\circ} \mathrm{C}\right)$, change of mental status (50\%), productive cough (50\%), and unproductive cough $(36 \%)$. Contrary to the literatures, only a small proportion of patients reported diarrhea (29\%), abdominal pain $(29 \%)$, nausea and vomiting $(21 \%)$, headache $(14 \%)$, fatigue (29\%), and myalgia (21\%). Patients were more likely to present with unilateral airspace disease (64\%) than bilateral airspace disease (36\%) on chest xray. The median sodium, phosphate and creatine kinase were $133 \mathrm{mmol} / \mathrm{L}, 0.84 \mathrm{mmol} / \mathrm{L}$, and $440 \mathrm{u} / \mathrm{L}$ respectively. The severity of illness was high in this cohort reflected by a median Pneumonia Severity Index of 119.8 (57\%) were considered likely whereas 6 (43\%) were considered very likely to have LP based on the WUH point score. The median presenting WUH point score was 15. 4 (29\%) had delayed antibiotics therapy (> 24 hours). 6 (43\%) received fluoroquinolone, and $10(71 \%)$ received macrolide. $9(64 \%)$ required endotracheal intubation with a median length of ventilation of 10 days. 8 (57\%) required vasopressive support and $5(36 \%)$ required renal replacement therapy. 3 (21\%) died. 11 (79\%) required intensive care unit (ICU) admission with a median ICU length of stay (LOS) of 14 days. The median hospital LOS of all patients was 11 days.

\section{Conclusions}

LP is a serious form of CAP that carries a high mortality rate despite appropriate antibiotic therapy. Symptoms of LP were not always consistent with the literatures but the WUH point score was helpful. 


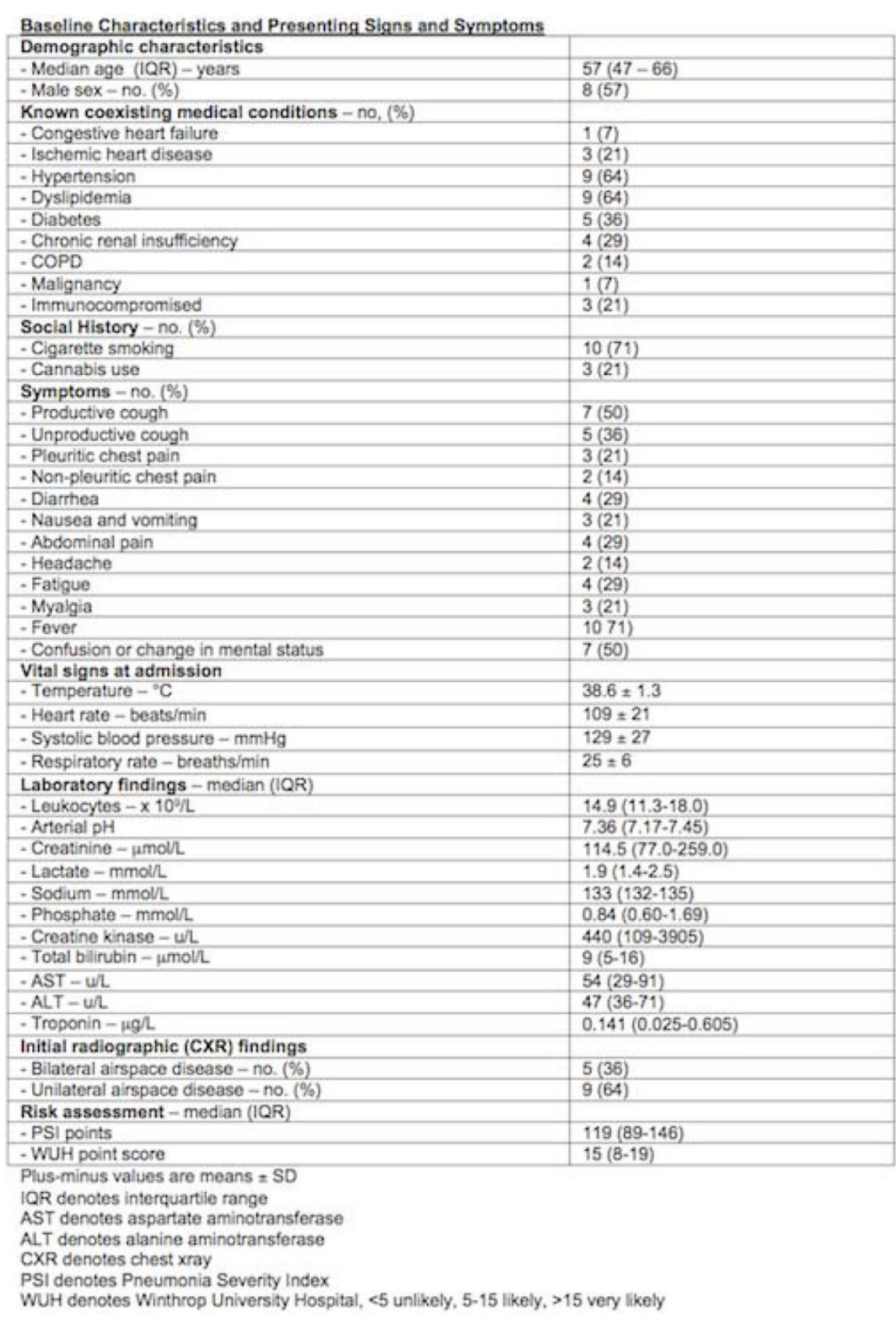

Figure 1 Baseline and Presenting Characteristics.

Clinical Course and Therapies

\begin{tabular}{|l|l|}
\hline Clinical course & \\
\hline - ICU admission - no. (\%) & $11(79)$ \\
\hline - ICU length of stay - median days (IQR) & $14(6-21)$ \\
\hline - Hospital length of stay - median days (IQR) & $11(7-25)$ \\
\hline - Mortality - no. (\%) & $3(21)$ \\
\hline Therapies & \\
\hline - Fluoroquinolones - no. (\%)* & $6(43)$ \\
\hline - Macrolide - no. (\%)* & $10(71)$ \\
\hline - Delayed in appropriate antibiotics (>24H) - no. (\%) & $4(29)$ \\
\hline - Intubation - no. (\%) & $9(64)$ \\
\hline - Length of ventilation - median days (IQR) & $10(7-11)$ \\
\hline - Vasopressor - no. (\%) & $8(57)$ \\
\hline - Renal replacement therapy - no. (\%) & $5(36)$ \\
\hline
\end{tabular}

ICU denotes intensive care unit

BIPAP denotes bi-level positive airway pressure

*Some patients were treated with both fluoroquinolone and macrolide

Figure 2 Clinical Course and Therapies. 


\section{Authors' details}

'Michael G. Degroote School of Medicine, McMaster University, Niagara

Region, Canada. ${ }^{2}$ Niagara Health System, Medicine, St. Catharines, Canada. ${ }^{3}$ University of Toronto, Medicine, Toronto, Canada. ${ }^{4}$ Toronto East General Hospital, Toronto, Canada. ${ }^{5}$ McMaster University, Mediicine, Hamilton,

Canada. ${ }^{6}$ Niagara Health System, Medicine, Niagara Region, Canada.

Published: 1 October 2015

doi:10.1186/2197-425X-3-S1-A352

Cite this article as: Cargnelli et al:: A case series of legionella

pneumonia in the niagara region, canada. Intensive Care Medicine

Experimental 2015 3(Suppl 1):A352.

\section{Submit your manuscript to a SpringerOpen ${ }^{\mathcal{O}}$ journal and benefit from:}

- Convenient online submission

- Rigorous peer review

- Immediate publication on acceptance

- Open access: articles freely available online

- High visibility within the field

- Retaining the copyright to your article

Submit your next manuscript at $\gg$ springeropen.com 